\title{
Pervasive death: Teresa Margolles and the space of the corpse
}

\author{
Edward Bacal University of Toronto \\ edward.bacal@mail.utoronto.ca
}

\begin{abstract}
I focus on two contemporary art installations in which Teresa Margolles employs water used to wash corpses during autopsies. By running this water through a fog machine or through air conditioners, these works incorporate bodily matter but refuse to depict, identify or locate anybody (or any body) within it. Rather, Margolles creates abstract works in which physical limits - whether of bodies or of art works dissolve into a state of indeterminacy. With that pervasive distribution of corporeal matter, Margolles charts the dissolution of the social, political and spatial borders that contain death from the public sphere.

In discussing these works, I consider Margolles' practice in relation to the social and aesthetic function of the morgue. Specifically, I consider how Margolles turns the morgue inside out, opening it upon the city in order to explore the inoperative distinctions between spaces of sociality and those of death. In turn, I consider how Margolles places viewers in uneasy proximity to mortality, bodily abjection and violence in order to illustrate the social, political and aesthetic conditions by which bodies become unidentifiable. I ultimately argue that her aesthetic strategies match her ethical aspirations to reconsider relations to death, violence and loss within the social realm.
\end{abstract}

Key words: Teresa Margolles, contemporary art, abstraction, Latin American art

\section{Something in the air}

When approaching an artwork such as Aire ('Air', 2003), an installation by the contemporary artist Teresa Margolles, viewers are most likely to be struck by the lack of anything particularly striking about it. The installation simply consists of two air conditioning units standing in adjacent corners of a relatively small room, as well as curtains of transparent plastic strips that loosely seal off the room's openings, insulating it with a minimum of visual interference or physical restriction. ${ }^{1}$

With these few elements, Margolles invites viewers into an all but blank space wherein the concentration of cooled air is immediate, registering itself as it touches upon one's body, penetrating one's clothes and chilling one's skin. For those entering without familiarity with Margolles' practice, this installation is by all appearances 
anodyne; nevertheless, as they read the wall texts that usually accompany her works, they learn that the air conditioners, which require water to cool and humidify the air they produce, employ water used to clean the bodies of anonymous murder victims. By running these machines constantly, Margolles disseminates the traces of these dead bodies throughout the gallery, effectively spreading them through the work's atmosphere. A kind of uncanny surprise arises as this mundane machinery reveals its necrological implications; namely, that the presence of death pervades our environment without our realising it. In so far as viewers sense the immanence of the dead body - and so death itself - in their immediate space, they will likely have different reactions to this work, ranging from indifference to intense feelings of horror, shock or fascination. And yet, this entire experience occurs in the absence of any discernible body, at least one we that can perceive as such. The reflexive revulsion of seeing a corpse is replaced with an uncertain perception of it, perhaps an awareness of the utter banality of death as something simply in the air.

As this installation demonstrates, the work of Teresa Margolles is remarkable for its close engagement with death and for the stark economy of aesthetic means by which it explores the imperceptible realities of violence. Margolles' concern for the social, political and material conditions embodied in corpses, particularly anonymous victims of widespread violence and destitution, has led her to combine material traces of the violated body with the formal strategies of post-minimalist and conceptual art. This includes, but is not limited to, immersive installations that draw their symbolic and affective power from their use and treatment of materials, including the physical residues of human corpses and detritus from murder scenes.

This practice reflects Margolles' training in forensic science and her experience working as a morgue technician. ${ }^{2}$ Given that institutional relation to the dead, Margolles reiterates the physical and symbolic space of the morgue within her work, simultaneously invoking and troubling a forensic gaze. While she has often depicted corpses directly, her work is significant for the ways it separates the corpse from its own image. That is to say that she employs abstraction in ways that challenge the presumption of an inherent correspondence between object and subject and between image and identity. In probing the limits and impossibilities of those relations, she explores the aesthetic possibilities that come with separating the material traces of bodies from the figure of the individual. Moreover, her examination of the human body as base matter - of human life in the absence of any subjective form challenges assumptions about how the human itself functions within modern sociopolitical structures. In these ways, the abstract material traces that she employs index the social relations that produce the invisibility, disappearance and anonymity of certain corpses. Her work thereby takes stock of the socio-political and ethical urgencies of mourning an unknowable body, in protest of the state structures that facilitate a seemingly unlimited production of death.

With these concerns in mind, this article discusses Margolles' works that incorporate human corpses but simultaneously conceal, dilute or redistribute them beyond recognition. I focus on Aire and Vaporización ('Vaporization', 2003), two of many installations where Margolles employs water used to wash cadavers during autopsies. With these examples, I examine the means by which she negotiates 
the simultaneous presence and absence of the corpse, arguing that her pervasive distribution of corporeal matter - a distribution of spectral absence - charts the dissolution of the social, political and spatial borders that contain death from the public sphere. In turn, I consider how Margolles places viewers in uneasy proximity to mortality, bodily abjection and violence in order to illustrate the equally sociopolitical and aesthetic conditions by which bodies become base matter. I ultimately argue that her aesthetic strategies match her ethical aspirations to reconsider our relation to death, violence and loss within, and as constitutive of, the polis.

\section{Aesthetic responses to socio-political exigencies}

Teresa Margolles has built her career alongside the social, political and artistic context of contemporary Mexico. Beginning with her participation in SEMEFO, a metal band-turned-art collective, her artistic practice began in Mexico City at the start of the 1990s. ${ }^{3}$ Since then, her work as a solo artist has continued to chart the vicissitudes of Mexican society, although increasingly on a broader art-world stage, including major international projects throughout Europe and the Americas (for example, she represented Mexico in the 2009 Venice Biennale). Given the nature of her practice, attitudes toward her art have typically been mixed. She has courted much critique and dismissal on the part of viewers and critics who see her work as an art of sensation and shock. To be sure, this reaction is principally aimed at her relatively jarring techniques, which arguably flout conventions of moral taste and ethical practice, bordering on a kind of nihilism or empty sensationalism. Particularly problematic is her use of dead human biomatter, which appropriates the matter of bodies that have not consented or cannot consent to that application. Moreover, when Margolles does acquire the consent of kin, it is often in circumstances where the latter's incentive to cooperate is largely born of socio-economic disparity; for example, Margolles has covered the cost of burial where the deceased's family cannot afford it. ${ }^{4}$ As such, Margolles' aestheticisation of death, violence and destitution, usually by way of abstract artworks that rarely explicate their intents and purposes, is liable to cause anxieties among viewers who are inclined to see her work as taking advantage of abject conditions to generate controversy. From this perspective, one may ask if it is ethical - if it is right, proper or respectful - to make and exhibit these works. Is the artist, along with the institutions that display her work and the viewers that consume it, complicit in the spectacularisation of the conditions she ostensibly critiques?

These questions are certainly relevant, and while I think they miss much of the nuance and critical potency of Margolles' practice, I am not interested in simply dismissing them. That said, a full overview and repudiation of these critiques is unfortunately outside the scope of this article; however, I believe my analyses of her work will indirectly respond to these claims, arguing against the underlying assumptions and attitudes that inform them. Central to this is an attempt to think against a kind of humanist morality that instinctively views the corpse in the same terms as it does the living human subject, complete with a sense of $a$ priori agency and dignity. As I argue, Margolles challenges these assumptions to interrogate the 
ways that life, death and the human are socially and discursively constituted, and to consider the corpse's material specificity outside of commonplace attitudes. This is not to degrade, or foreclose respect for, the corpse but to consider its political and ethical potency as something other than a proxy for a subjective erstwhilelife. The question of ethics that Margolles raises is therefore less 'Is it right to display her works?' and more 'How do we exist alongside the corpse, as something that upsets our received assumptions about the integrity of life, death and the body?'

To address these questions, it is necessary to touch upon the historical circumstances that Margolles' work has evolved with. To offer an admittedly rushed overview, her practice emerged during a new period of social upheaval and instability in Mexico, particularly following the social and political shifts encapsulated by the North American Free Trade Agreement (NAFTA). The signing of NAFTA in 1994, followed by economic crises and the destabilisation of state power, also signalled the rise and collapse of industrial towns along the Mexico-US border. Having largely emerged to complement the newly deregulated import of cheaply produced goods into the US, these towns (most infamously Ciudad Juarez) have become notorious for incredible levels of violence that have become all but normal in daily life (for example, 27,199 murders were recorded throughout the country in 2011, amounting to around 24 murders per 100,000 people. In Ciudad Juarez, whose population falls under 1.5 million inhabitants, 3,116 murders were reported in 2010 , amounting to about 8 a day). ${ }^{5}$ With the implosion of local economies and the coincident growth of the drug trade, these regions have become new hubs for the transit of cocaine northward, and so have become subject to the informal dominance of narco-traffickers. This has meant the proliferation of gang fighting, executions, kidnappings, femicides and vendetta killings. Furthermore, the spectacularity of this violence, in its pervasive mediatisation and theatricality, has amplified the visibility of dead and dismembered bodies in images and in public view, providing a rich source of scandal in news reportage and political discourse. More generally, the presence of death has made itself dramatically more immediate, as the frequency of murders and the sight of corpses have become increasingly familiar in everyday life. Where this violence had traditionally been limited to those within the crime underworld, since the 2000s it has spilled over to broader facets of society: bystanders, police and military, female factory workers, journalists, family of narco-traffickers and others uninvolved in the drug trade have all recurrently figured as murder victims. More than just a surge in crime, then, the seeming indiscriminateness by which violence extends to potentially anyone indicates a condition of terror, in so far as it becomes possible to imagine anyone as a corpse in the street, a body in a mass grave or raw flesh in the morgue. There is a perverse levelling in this indiscrimination between who can be killed, reminding us that here, as Margolles explains, 'social conditions that could guarantee anyone's life do not exist.' 6

The state has responded in kind, unleashing a contentious war on drugs - most dramatically under Felipe Calderon's administration in the late 2000s - for which an uncompromising police and military response has exacerbated violence to an even 
greater level. Given the state's attempt to recover a 'monopoly on legitimate violence' via militarised clampdown, and given popular and official rhetoric that justifies the killing of citizens by implying that violent death is merely the price one pays for entering the drug trade, a quasi-state of emergency and exception has taken hold throughout much of the country. ${ }^{7}$ The state struggles with gangs to maintain control over territory, it exercises the sovereign privilege of deciding the point at which killing citizens is legitimate, if only as the justification of its own means and ends of control. As Cuauhtémoc Medina notes, 'We cannot, therefore, but detect a close relationship between the atrophy of a democracy helpless to implant itself by the force of its measured violence, and the hypertrophy of the sovereignty of a sacrificial practice that does not aspire to political hegemony: it merely seeks to tighten control over this necessarily fluctuating commerce, whose illegality turns it into an particularly deregulated branch of contemporary capitalism.' ${ }^{8}$ In this sense, the Mexican war on drugs dredges up the sacrificial function of sovereignty, as Georges Bataille and his followers have theorised it. ${ }^{9}$ Born out of an originary violence, sovereignty finds its essential function in transgressing the limits between life and death; that is, in the excessive production of death that comprises sovereignty's own unregulated economy of sacrifice. ${ }^{10}$

This is the also sense in which Achille Mbembe theorises sovereignty in terms of 'necropower', whereby politics consists in the 'generalised instrumentalization of human existence and the material destruction of human bodies and populations. ${ }^{11}$ Mbembe, rejecting the idea of sovereignty as the governing of autonomous subjects within a community bound by reason, posits life and death as foundational political categories for the respective bio- and necropolitical operations of the state. The sovereign exercises power, qua necropower, in its self-legitimising control over the production of death. As a prominent example of necropolitical operations, Mbembe discusses modern warfare as an exercise in dividing populations into different biological categories, corresponding to those who may and may not be justifiably killed. In distinction to traditional forms of war, conceived as a rule-governed contest between states, we see a collapse between the means and ends of war in its informal, necropolitical guise. ${ }^{12}$ War becomes a function of the sovereign expenditure of death, a reflexive justification and enactment of the sovereign prerogative to take life. War is both without ends, in terms of instrumental justification for its means, and without end, in that it guarantees an indefinite state of exception for which the sovereign may extend its control over life and death beyond the distinction of war and peace time. As Medina then explains, reflecting on the state of Mexico in the wake of its war on drugs, 'we are drifting into a normalised management of conflict, designed to secure the immortality of democratic capitalism by means of everlasting wars without truces or victories. ${ }^{13}$ And further, 'we have the proliferation, theatricalization and inexorable progression of a violence that is spectacular and without measure $:{ }^{14}$ with the transgression of the limits between life and death, and in the absence of social conditions that, pace Margolles, protect anyone's life, the generalised presence of death bespeaks its extension beyond the social, juridical and political limits that we expect to contain it. 


\section{Bodies at their limits}

How do these contextual circumstances figure into Margolles' work? The answer varies with each project and the particular means by which she carries it out, especially since she typically does not posit direct commentary or explanation from which we might read a particular position. That is not to say that she dissembles any political opinion or purpose, nor denies her art its capacity to voice protest; rather, she prefers to index political reference points by allowing her materials to draw out their existing significance, if not also their qualitative insignificance. Her work puts pressure on the epistemological and perceptual grounds for representing death and violence, particularly when it comes to communicating particular lives lost. In place of an inferential analysis, she explores the spectral qualities of materials and experiences as the repository of social and ethical relations that cannot be readily figured.

With these concerns in mind, the most useful starting point for discussing Margolles' work is the human body, including its fragmentation, dissolution and absence. Margolles' innovative and often notorious use of human bodies and biomatter, whether in representational, abstract or performative ways, speaks to the different ways in which the body serves as a material measure of social and ethical conditions. Whether preserved - either in life or in death - or destroyed, brutalised or protected, honoured or forgotten, marked or unmarked, the body and biomatter index qualitative conditions of life: its socio-economic value, its subjection and subjugation and its social relevance, all of which are performed upon and through the body. Flesh becomes a carrier and, in certain circumstances and to certain degrees, a marker of the body's existence as a social and political object. As Coco Fusco, discussing SEMEFO's work in a distinctly post-NAFTA register, explains, this art 'doesn't champion the sanctity of the body but underscores the desacralizing of life that is the suppressed underside of Mexico's ongoing economic crisis. ${ }^{15}$ For these reasons, the body, its by-products and its material traces serve as privileged media for Margolles, who finds a lived social history embedded within them. The body's presence, as well as its absence, serves as both the material and immaterial foundation for Margolles' aesthetic and social interventions.

At the same time as Margolles calls forth a body she also dispels it, alleging it as the abstract imprint of its disappearance, the material trace of its dematerialisation. Her use of indexical remainders represents the difference between presenting an absence and tracing the body's disappearance from presence; it presents signifiers that do not conjure particular bodies as much as they expose the material traces of disappeared referents, reflexively performing the temporal and spatial disjunction inherent to any signifier. Much of this effect - this kind of spectral materiality, iterated in the present imprint of a disappeared figure - comes down to the specific materials Margolles uses: residues and remains that attest to a body and to a life, as well as to the negation thereof. These materials range from unadulterated human biomatter such as blood, fat and sweat to sundry matter taken from places where murdered bodies were found. In both cases, there is a physical and spatio-temporal specificity to these the materials, in the direct and intimate relation of bodily fluids 
to a body or of incidental materials to a corresponding scene; however, these fluids do not amount to a body or its image, nor do they explicate the forensic details of who, what, where, why, when and how such a body existed. In sum, Margolles invokes a certain singularity, promising the existence of a real referent but stops short of offering positive knowledge of it.

\section{Water, air, fog}

These effects are best expressed in works where Margolles sources water from the morgue. As a method for transmitting the physical traces of corpses, she preserves and recycles the water she uses in the standard practice of washing corpses in preparation for forensic examination. To be sure, the water is heavily sanitised, such that the smell of antiseptic will typically overshadow the presumed smell of a cadaver's remains. Nevertheless, this water serves as a particularly effective medium for dissolving the body's material traces into a fluid form, which one can then redistribute in otherwise impossible ways. Given its fluidity and the wide range of possibilities it opens for material exploration, water lends itself to countless different forms, applications and manifestations, whether in works that are solid, liquid or vaporous. For instance, Margolles has mixed this water with cement to create concrete benches (e.g. Untitled, 2010), giving a stable and lasting form to an otherwise elusive material. She thereby preserves water in forms that are solid and available to physical contact, as one can readily sit on a bench for extended periods of time, pressing and conforming one's own physical figure to a solid mass. In a different way, Aire runs this water through air conditioners, spreading it so thin that it becomes impossible to distinguish from its surroundings, becoming all but perceptible. And in Vaporización she runs this water through fog machines, multiplying its surface area and spatial reach by turning it into a pervasive ether that is tangible yet nebulous. As these works demonstrate, water, regardless of its internal content, is practically and formally useful for experimenting with the materiality of art objects. Lacking any given shape, figure, distinct surface or unity of form, water is in certain ways a kind of post-minimalist 'anti-form' material par excellence: its fluidity perfectly embodies the tension between the material and immaterial that occurs at the contingent and fluctuating limits of form itself.

Water also represents a kind of theoretical analogue for the body as Margolles conceives it. Like the water in these works, Margolles' bodies exist in their fluidity. Endlessly divided and multiplied, spread across a plurality of surfaces and things, and manifest in different shapes and textures, these bodies are without distinct beginnings or ends. Even as these bodies pervade the water that hosts them, it remains impossible to locate bodies within it, to discern the physical limits that would constitute a figure. As such, these bodies represent neither an absence nor a presence but an aporetic condition in which they are simultaneously there and not there. The body exists as an instance of empirical negation, such that we can take its existence only as a matter of faith. ${ }^{16}$ The materially specific biomatter of a singular being is contained in the water, yet no such matter is perceptible; or rather, the body neither appears nor functions as a body: its bodyness does not take place in what we 
typically think of as a body; namely, the biological figure and biological figuration of an autonomous existent. But Margolles offers no such things. The body, and more precisely the corpse, not only fails to express itself in the legible shape or figure of a bio-ontological unity but exists in its disunification, distention and dissolution. Margolles dissolves the body into something that is almost nothing, a material that borders on the immaterial, but also, perhaps, an immateriality that touches upon the material. As Klaus Görner and Udo Kittelman explain, in these works, the remains of life 'hover at the very limits of the depictable, at the limits of art, precisely where death - beyond all symbolisation - just manages to remain visible as the dissolution of form. ${ }^{17}$ I take this to mean that form exists at the point of its disappearance, in the emptying out of meaning and dissolution of figure that remains in the place of life or a body. In this way, as Gabriela Jaregui notes, Margolles' 'art is defined by the tension between thingness and nothingness: ${ }^{18}$ it moves between something some thing, some body, somebody - and nothingness, preserved in a state of ontological suspension. To reiterate, the work is not a present marker of an absent form but marks the absenting of form. As an indexical marker of bodies that in fact exist, what does this water index? The answer, I argue, is the spectral materiality of a body that marks the limit of its (dis)appearance.

To follow this argument, let us return to Aire, which matches a lack of discernible phenomena with the contact of morbid matter, establishing a paradoxical experience of the abject. While the implication of the corpse upon the viewer's own body is likely to produce visceral reactions, the power of such sensations also points to certain contradictions at the core of the work. In particular, I would argue that the viewer's affects not only exist outside of a perceived object to project them onto, but are born of the absence of an object of affective relation to begin with. Knowledge of the air's composition is potentially disconcerting, despite the lack of empirical basis for it: viewers may sense the proximity and possibly the invasion of the abject, and perhaps feel it compromising their embodied integrity by polluting their personal space. At the same time, this proximity is equally a distance, calling into question the material limits of the corpse itself, as something hardly contained by the limits of flesh, nor by its appropriate institutions (i.e. the morgue or the grave). Margolles simultaneously disseminates and conceals the corpse; she produces dead bodies without conjuring bodies themselves. Through the corpse's contact with the morgue water and its subsequent passage through air conditioners, what is solid melts into air. The substance of the work, the presence of death, is therefore invisible: Margolles insinuates the corpse as little more than a mild transformation in the room's climate, something one experiences as a change in atmosphere rather than a confrontation with a discrete object. It is therefore uncertain whether it is this contact with death or simply the cold air that might give viewers goose bumps, but it is also uncertain whether such a distinction between the absent presence of death and its material manifestation holds. This work registers the corpse, in its imperceptibility, as an environmental quality to be felt only indirectly as the sensation of something touching upon one's body without ever being there. In this sense, the work recalls the popular trope of feeling a chill when coming into contact with a ghost, whose spectral presence cannot show itself but can alter general conditions of perception. 
Bodies never truly touch, yet viewers experience a contiguity or adjacency with other bodies, occurring in the chain of material indices that transpose the limits of one's body over those of another.

Similarly, Vaporización runs morgue water through fog machines in order to flood its containing room with a pervasive haze of vapour, turning the gallery into a translucent space stripped of images or legible figures, notwithstanding the different swathes of fog that pump out of machines and the relatively vague impression of lights and other bodies in the room. One gets a marked limiting of the field of vision: where Aire engages the corpse by concealing it, presenting it on the condition of its invisibility and with a minimum of visual mediation, Vaporización renders the visual homogenous. Fog reduces the gallery to a diffusely illuminated and spatially nebulous environment, causing edges to fade and fields of depth to become radically flattened. It also impacts on the experience of time, arguably causing viewers to slow their movements and pace themselves as they take more careful stock of their positions and perceptions, if only to avoid bumping into something, but also to reconcile a simultaneous diminution and amplification of perceptual stimuli. In distinction to Aire, which seems to confound viewers by presenting something that appears to be little more than nothing, Vaporización literally clouds viewers through palpable, multi-sensory immersion. One experiences the work in a state of affective intensity, which consists in the experience of abstraction; which is to say, the sensation of objects that have been unfixed from physical position, shape and form.

For these reasons, we can read Vaporización and Aire in the tradition of phenomenologically informed art theory, which has since the 1960 s theorised the lived conditions for experiencing artworks. ${ }^{19}$ Along those lines, the immersive installation trades art's more traditional iconophilia and scopophilia for a spatio-temporally situated experience that decentres the artwork, dislocating it from a particular object in order to reiterate it as an unfixed assembly of affects and percepts. The installation affords viewers an awareness of their own bodies in space and time and potentially distends that qualitative experience through aesthetic intervention. The body as visual object or apprehensible figure has disappeared; in its place, Margolles offers an abstract sensation of the body, an implication of it that emerges as viewers move their own bodies through the wall of vapour or air, feeling it, smelling it, tasting it, breathing it in, absorbing it into their lungs and skin, inhabiting a space where the limits between the body and its environment, and no less the limits of the body itself, lose distinction. Yet this model is also limited: in the experience of something we cannot know - the existence of dead bodies that viewers share the gallery with - and the knowledge of something we can't experience - death - we come upon the work's phenomenological limits. At the same time as the work causes viewers to position themselves within the installation, in an experience of spatio-temporal specificity, it questions what viewers are in fact positioning themselves in relation to; that is, it challenges the supposition of establishing relations to the work in the absence, but also in the paradoxical presence, of an implied non-object.

In sum, Margolles' abstract invocation of corpses suggests the body's presence while simultaneously withdrawing it, rendering the corpse omnipresent within the gallery while also erasing it. In its indexical formation, the body is there but is also 
nowhere; it exists yet never appears; it is markedly absent, yet its absence contains traces of a disappeared presence; it is there as an uncertain trace, since we cannot trace these remnants back to any particular body. In this essentially spectral quality, through which bodies haunt space without constituting themselves as bodies within it, Margolles' work questions whether the corpse constitutes a positive relation to the viewer. It asks if a subject-object relation occurs in the absence of shared presence or of perceptual or epistemological recognition. The answer seems to be no, because the work retracts any relation one might conceive to a body or bodies that we can imagine as such. One's bodily experience of the work occurs in the dissolution of a relation between bodies in space. If these works function to place viewers in contact with other bodies, specifically other dead bodies, one finds oneself unable to measure one's own body against reciprocal bodies and objects. As vapour or air immerses the viewer, entering one's porous limits, the reflexive experience of one's body occurs at the negative limits of bodies without borders, the physical and ontological unlimiting of bodies that one normally takes as distinct. To be sure, it seems unlikely that viewers will experience the work as some sort of out-of-body experience, to put it crudely, or to lose sight of the horizon of perception that grounds their experience; nevertheless, in the absence of a body with which to establish a mutual phenomenological relation, and in the perception of sensations divorced from objective qualities, one may experience something like the immediacy of a spectral chill or distention of time and space. And the corpse seems particularly apt in engendering this uncanny sensation.

\section{The epistemology of the morgue}

While these installations rely on their immediate physical settings - the gallery interiors that concentrate air or fog - they equally speak to a number of other spaces that Margolles' media moves through. Most significantly, her works with water testify to the corpse's passage through the morgue, which includes Margolles' position therein. The morgue is both a privileged and problematic space for the artist, who has foregrounded its role in her art since the beginning of her career. For instance, in 2000 the artist fashioned her practice via her photographic series, Autorretratos en la Morgue ('Self-Portraits in the Morgue'), which included, to name one example, an image of her standing in a white lab-coat next to a tank of clouded water, holding the brutal corpse of an adolescent girl in her arms, pietà-style. Like so many portraits of artists in their ateliers, these works document Margolles' working method and assert what her art entails: an attempt to communicate the otherwise closedoff realities of what the morgue witnesses; namely, an unrelenting, remorseless and non-transcendent production of often-anonymous death. ${ }^{20}$ In that way, her work aims to transmit into public space the unflinching contact with dead bodies that occurs in the morgue, exposing the broader social realm to the inner workings of death's private spaces. Her redeployment of water transposes the morgue and the gallery, placing these seemingly incongruous milieus into virtual contact.

While Margolles bridges these realms, she also suggests that they are never really separate to begin with. The larger geographic itinerary of her water encompasses 
the body's transitions from public space to the morgue and back, mapping a synecdoche of life and death in Mexico more broadly. As the artist explains, the water she takes from the morgue is the same water that also gets washed away in the river and eventually rains back down upon Mexico city. In turn, that rainwater is absorbed into other bodies and into the earth, washing both the streets and the corpses that lie there before being taken to the morgue. ${ }^{21}$ Comprised of these innumerable, untraceable passages through Mexico City's plumbing, rivers, water table and rain cycle, water maintains its own life through which it accumulates innumerable different residues, all of which move in and out of the morgue. ${ }^{22}$ The latter thereby represents a junction for these different social and geographic trajectories to converge; it also thereby represents a real and symbolic crux for Margolles' practice, which aims to reveal the morgue's constitutive role in an economy of anonymous death that pervades the city. As the artist notes, the morgue acts as a barometer for society: 'What happens in a city morgue is what happens outside, ${ }^{, 23}$ she states, affirming the mutual constitution of these different spaces. From there, she aims to rebut the assumption that the morgue, as symbol of the corpse in its base materiality, is a space of containment, a quarantine of death from the space of the living; instead, she posits the morgue as a metonymic expression of the vital and violent social forces and relations that contribute to the endless production of death that implicates the polis in general.

At the same time that Margolles invokes the morgue, she also complicates its relation to the corpse and its presentation. To be sure, the morgue has cast on long shadow on visual and popular culture - not to mention scientific and civic culture dating back to at least the nineteenth century, when the Paris morgue drew up to 40,000 patrons in a day to view corpses. ${ }^{24}$ As the primary site for mediating interactions between the public and the dead (not including the cemetery, where death is literally buried away and largely ritualised), the morgue sets its own institutionalised relation to the corpse as an object of perception, particularly as something to perceive objectively. The morgue's claim to ostensible scientific and institutional disinterest distances death's immediacy by supposing an instrumental relation to death and the dead body. It is there that one treats the body precisely as inanimate matter, perceiving it in terms of its biophysical facticity. For Margolles, however, it is a site in which to up-end the function of her chosen forensic methodology, which conventionally uses material evidence - the corpse, and whatever matter it has been in contact with - to deduce the body's identity in life and the conditions of its death. Where, as Rebecca Scott Bray notes (referring to a series in which Margolles took close-up photographs of cadavers), 'Autopsies function to explain death to "help the living. ..", Margolles' works 'establish nothing of identity even when they highlight a key individual semiotic fragment [such as] a tattoo. ${ }^{25}$ Margolles resists the urge to present the dead body as more than a dead body, to perceive it on the condition that it corresponds to a particular subjectivity or identity; rather, the material specificity of the corpse qua corpse takes the place of the body as something knowable. To these ends, David Francis summarises that 'Margolles employs our understandings of the morgue to invert our expectations of perceiving (or cutting into) the dead and its interior. In spite of her academic training, what the artist appears to be 
elucidating becomes a hermeneutics of contemporary misapprehension, where the body and the cause of its death are intimated in the space of attempted perception, where our desire to perceive differently is just as important as our incapacity to do so completely. ${ }^{26}$

In these ways, Margolles inhabits the morgue as a kind of heterotopia, to use Michel Foucault's term for the 'other spaces' that simultaneously exist within and without society's normalised structures. ${ }^{27} \mathrm{Or}$ as Medina states, drawing upon Foucault: 'To operate within the morgue, and upon its content and purpose; to operate from this "space outside" allowed Margolles to realise a "heterotopy": a description or reading of a territory that appeared as a "refutation, both mythical and real, of the space of life"' ${ }^{28}$ For Margolles, then, the morgue provides an interstitial space where she can renegotiate the distinctions between life and death and between living and dead. By exploiting the morgue's privileged access to society's excess of human expenditure, she demystifies this site and, furthermore, reveals its inextricability with the social realm. That is, she inhabits this institution without necessarily subscribing to the relations it institutionalises. To be sure, the chance encounter between the artist and an anonymous body (very possibly on an actual dissecting table) is made possible by this institution at the same time that Margolles assumes a critical position within it. In particular, she avoids taking an instrumental relation to death that would see the corpse as a distinct object, isolated from the life of the polis and the polis of the living. Likewise, she does not explain away death in terms of forensic causality but draws out what exceeds its objectivity, namely, the material indices of an inappropriable morbidity. Finally, by redistributing these traces, her aesthetic inventions extend this heterotopia into the gallery and further into public space, allowing the presence of death to become pervasive, but not without eluding our immediate perception.

Despite the significance of this working method, Margolles has since moved past her mortician's post, deeming it unnecessary when the proliferation of public killings has meant the corpse is no longer something obscure. Since the late 2000s particularly with the rise of Northern Mexican drug wars - Margolles' work has seen her take her forensic approach outside of its institutions and into the streets, focussing on the public spaces where violence occurs and where bodies are found. In other words, she has moved from the corpse itself to what is left in its place, ${ }^{29}$ retaining her quasi-forensic methodology but cutting out the proverbial middleman by going straight to crime scenes. There, she collects 'evidence' of the corpse's presence as it is directly embedded in the city. For example, this includes works like Sonidos de la Muerte ('Sounds of the Dead', 2008), an audio installation which presents field recordings of murder scenes. While asserting a direct physical relation to a site of violence, the work seems to almost parody the idea of deductive inquiry that we associate with forensic investigation. The work collects evidence, tracing the spectral presence of violence and death much as one would trace a body with chalk, but any evidence it records amounts to all but nothing; that is, nothing translatable into legible signs of identity or narratives of murder. Instead, it offers the stillness of a plain field recording, haunted by the implication of an act that once occurred, an event that this recording could not itself actually record. The 
archival function of such impressions is therefore moot, in that we cannot trace this evidence back to any person, time or even place, for these recordings offer no information beyond the spectrality by which they document a vague something that happened somewhere. It is evidence that doesn't have a clue. Indeed, Margolles seems content to leave us uncertain, going through the motions of capturing indexical impressions of violent scenes, but confounding the evidentiary function of such indexes. She compiles archives of evidence that forego their legibility in order to elude their application as inferential documents, offering instead what Medina calls 'a heterodox experience of knowledge and an ethical investigation pushed to the limit'.

What we can ultimately take from Margolles' work is this final idea of an experience, particularly an ethical experience, that occurs at the limit of our apprehension. In that respect, all of Margolles' media serves a similar function, whether she compiles it inside or outside of the morgue. By emptying materials of inferential value, she rejects a biomedical or forensic will-to-knowledge, and so any instrumental relation to the corpse born of a desire to know it. As such, she does not allow viewers to apprehend the corpse, but only the limits by which we fail to perceive the body of an anonymous death. Certainly, we cannot trace morgue water back to any identifiable person, only to bodies whose spectral materiality indexes a socio-political condition of indeterminacy. It is that condition, in its material specificity, that she attempts to draw out. In doing so, Margolles replaces a forensic gaze with an ethical position that forecloses the epistemological or phenomenological appropriation of the corpse: to encounter the body as it is - namely, as an anonymous corpse - is to respect it as such. It is not to mourn it or acknowledge it only on the grounds that we can perceive and relate to it as distinct object, one we can name, categorise, identify or identify with. Rather, to respect the material specificities of the corpse, as constituted in the socio-political production of its death and anonymity, is to paradoxically mourn the corpse as something we cannot conceive in a subject-object relation. Where mourning is traditionally understood as the disinvestment of libidinal cathexis upon an object of attachment, Margolles asks us to mourn those with whom we cannot assume such a relation. She asks us to reconstitute our relation to the dead by rethinking how we, who mostly presume ourselves to comprise a community of living embodied beings, meet our social and ethical limits in the encounter with that epistemological and ontological excess. This encounter takes the liminal form of the spectral presence of bodies we cannot perceive as such; bodies that lack distinct edges by which to separate one figure from any other, or from the world at large; bodies we cannot gaze upon as discernible objects nor pinpoint in an object such as an artwork; bodies that, in their anonymity and abjection, appear only at the point of their abstraction; bodies that do not represent a sacred life but trace a condition of insignificance; and bodies that refuse the material figuration of an individual subject. In staging this encounter, Margolles brings us to, and hence displaces, the limits that separate the world of the living from a world saturated with the dead; that is, a world where death is not only omnipresent, if only spectrally, but weighs upon the living in the constitution of social life itself. 


\section{Edward Bacal}

\section{Acknowledgement}

This research has been supported by a Social Sciences and Humanities Research Council doctoral fellowship.

\section{Notes}

1 I base my description of this work on its installation in London's Hayward Gallery in 2012, where it was included in the exhibition Invisible: Art about the Unseen 1957-2012. The specifics of the installation are subject to change with different iterations. Note: This work is not to be confused with the 2002 work of the same title, which uses humidifiers rather than air conditioners, nor with the 2003 work, En el Aire (In the Air), which uses bubble machines.

2 In addition to studying art, Margolles earned a degree in forensic medicine and science of communication from the Universidad Nacional Autonoma de Mexico. She has also worked professionally in the Mexico City morgue.

3 SEMEFO stands for Servicios Medicos Forensicos (Forensic Medical Services), named after the civic institution that collects corpses and delivers them to the morgue.

4 This is the case in Lengua ('Tongue,' 2000), which consists of a severed tongue that had belonged to a street youth, and Entierro ('Burial', 1999), a concrete block that entombs a stillborn foetus. In making these works, Margolles met with the families of the deceased to negotiate her adoption of the tongue and foetus, respectively. In the former instance, Margolles funded the burial, and in the latter she provided another kind of burial for the child, that would otherwise have been discarded as medical waste.

5 R. Fausset, 'Amid Drug War, Mexico Homicide Rate up for Fourth Straight Year', Los Angeles Times, 21 August 2012, http://latimesblogs.latimes.com/world_now/ 2012/08/in-midst-of-drug-war-mexican-homicide-rate-increase-for-fourthstraight-year.html, accessed 1 December 2016; N. Valencia, 'Juarez Counts 3,000th Homicide of 2010', CNN, 15 December 2010, www.cnn.com/2010/ WORLD/americas/12/15/mexico.juarez.homicides/index.html, accessed 1 December 2016.

6 T. Pimentel, 'Conversation between Taiyana Pimentel, Teresa Margolles, and Cuauhtémoc Medina', in C. Medina (ed.), Teresa Margolles: What Else Could We Talk About?(Colonia (Cuauhtémoc and Barcelona, EditorialRM, 2009), p. 93.

7 C. Medina, 'Materialist Spectrality', in C. Medina (ed.), Teresa Margolles: What Else Could We Talk About? (Colonia Cuauhtémoc and Barcelona, EditorialRM, 2009), p. 22.

8 Medina, 'Materialist Spectrality', p. 27.

9 See M. Botey, 'Toward a Critique of Sacrificial Reason: Necropolitics and Radical Aesthetics in Mexico, in C. Medina (ed.), Teresa Margolles: What Else Could We Talk About? (Colonia Cuauhtémoc and Barcelona, EditorialRM, 2009), p. 135.

10 A. Mbembe, 'Necropolitics', Public Culture,15:1 (2003), 16. 
11 Ibid., 14 (emphasis removed).

12 Ibid., 25.

13 Medina, 'Materialist Spectrality', 27.

14 Ibid.

15 C. Fusco, 'The Unbearable Weightiness of Being: Art in Mexico after NAFTA', The Bodies That Were Not Ours and Other Writings (London and New York, Routledge and InIVA, 2001), p. 75.

16 By this I mean to invoke the idea of 'faith' as something that exists only in the absence of a concrete or empirical presence. The matter - the materiality - of faith is in that sense born of its immateriality, and the experience of something that isn't there nevertheless is.

17 K. Görner and U. Kittelmann, 'Muerte Sin Fin', in K. Görner and U. Kittelmann (eds), Teresa Margolles: Muerte Sin Fin (Frankfurt, Hatje Cantz, 2004), p. 41.

18 J. Gabriela, 'Necropolis: Exhuming the Works of Teresa Margolles', in K. Görner and U. Kittelmann (eds), Teresa Margolles: Muerte Sin Fin (Frankfurt, Hatje Cantz, 2004), p. 177.

19 For example, see R. Morris, 'Notes on Sculpture', in G. Battock (ed.), Minimal Art: A Critical Anthology, (Berkeley, Los Angeles and London, University of California Press, 1995); R. Krauss, Passages in Modern Sculpture (Cambridge and London, MIT Press, 1981); R. Krauss, 'Richard Serra, a Translation', and 'Sculpture in the Expanded Field', in The Originality of the Avant-Garde and Other Modernist Myths (Cambridge and London, MIT Press, 1986).

20 The notion of the 'morgue-as-atelier' was formulated in Medina, 'Materialist Spectrality', p. 17.

21 A. S. Caroll, 'Muerte Sin Fin: Teresa Margolles' Gendered States of Exception', The Drama Review, 54:2 (2010), 115.

22 In this respect, Margolles' use of water is comparable to Hans Haacke's in the 1960s and 1970s. Haacke similarly filtered water through different kinds of machinery, creating circuits that both literally and allegorically represent the active social systems that are constituted in the gallery. In this respect, he provides a relevant aesthetic model for reading these works as such.

23 J. Banwell, Teresa Margolles and the Aesthetics of Death (Cardiff, University of Wales Press, 2015), p. 88.

24 V. R. Schwarz, Spectacular Realities: Early Mass Culture in Fin-de-Siècle Paris (Berkeley, Los Angeles, and London, University of California Press, 1998), p. 48. The Paris morgue also attracted a curious precursor to Margolles, Theodore Gericault, who similarly sought access to the morgue for his studies of decaying corpses and bodily fragments. These studies informed his masterwork, The Raft of the Medusa, another artistic protestation against the state's readiness to sacrifice the lives and bodies of its citizens.

25 R. S. Bray, 'Teresa Margolles' Crime Scene Aesthetics', The South Atlantic Quarterly, 110:4 (2011), 937.

26 D. Francis, 'In the Museum of the Mobile Anatomy Show', Performance Research, 19:4 (2014), 127. 


\section{Edward Bacal}

27 See M. Foucault, 'Of Other Spaces, Heterotopias', Michel Foucault Info, http:// foucault.info//documents/heterotopia/foucault.heterotopia.en.html, accessed 19 June 2015.

28 Medina, 'Materialist Spectrality', p. 18.

29 Ibid. 